\title{
Analysis of tooth decay data in Japan using asymmetric statistical models
}

\author{
This article was published in the following Dove Press journal: \\ Open Access Medical Statistics \\ 17 November 2012 \\ Number of times this article has been viewed
}

\section{Kouji Yamamoto' Sadao Tomizawa ${ }^{2}$ \\ 'Department of Medical Innovation, Osaka University Hospital, Osaka, ${ }^{2}$ Department of Information Sciences, Faculty of Science and Technology, Tokyo University of Science, Noda City, Chiba, Japan}

Correspondence: Kouji Yamamoto Department of Medical Innovation, Osaka University Hospital, 2-15 Yamadaoka,

Suita, Osaka, 565-087I, Japan

$\mathrm{Tel}+8166879568 \mathrm{I}$

Fax +81668795686

Email yamamoto-k@hp-crc.med.osaka-u. ac.jp
Background: The aim of the present paper was to develop two new asymmetry probability models to analyze data for tooth decay from 363 women and 349 men aged 18-39 years who visited a dental clinic in Sapporo City, Japan, from 2001 to 2005.

Methods: We analyzed the probability relationship between grade of upper and lower tooth decay for men and women using the two new models, and tested goodness-of-fit for the models.

Results: The probability that a woman's (man's) grade of lower tooth decay is $i(i=1,2)$ and her (his) grade of upper tooth decay is $j(>i),(j=2,3)$ is estimated to be at most $13.52(10.23)$ times higher than the probability that the woman's (man's) grade of upper tooth decay is $i$ and grade of lower tooth decay is $j$.

Conclusion: From the data on tooth decay, decay of the upper teeth is worse than of the lower teeth in women and men, and the tendency becomes stronger as the numbers of decayed upper and lower teeth increase.

Keywords: distance-proportional symmetry, asymmetry, square contingency table, teeth

\section{Introduction}

Consider the data in Table 1A and B. ${ }^{1}$ Table 1B shows data for teeth decay from 363 women and 349 men aged 18-39 years who visited a dental clinic in Sapporo City, Japan, from 2001 to 2005. Table 1A and B show the numbers of decayed lower and upper teeth. ${ }^{2}$ The categories are 0-4 decayed teeth; 5-8 decayed teeth; and $>9$ decayed teeth. From the data presented in Table 1A and B, it is likely that decay in the upper teeth is worse than in the lower teeth in both men and women. We are interested in using these data to determine the probability that a woman's (man's) grade of lower tooth decay is $i$ and her (his) grade of upper tooth decay grade is $j(>i)$ is higher than the probability that her (his) grade of upper tooth decay is $i$ and her (his) grade of lower tooth decay is $j$. For example, what is the probability that a woman's (man's) grade of lower tooth decay is 1 and her (his) grade of upper tooth decay grade is 3 is higher than the probability that her (his) grade of upper tooth decay grade is 1 and her (his) grade of lower tooth decay is 3 ?

Consider an $r \times r$ square contingency table with the same row and column classifications, as shown in Table 1 . Let $p_{i j}$ denote the probability that an observation will fall in the $i$ th row and $j$ th column of the table, and let $n_{i j}$ denote the observed frequency in the $i$ th row and $j$ th column of the table $(i=1, \ldots, r ; j=1, \ldots, r)$. Also, let $\hat{p}_{i j}=n_{i j} / n$ and $n=\Sigma n_{i j}$.

Table 2 gives (1) the values of $(i-1)+(j-1)$ (say, $\left.d_{i j}\right), i<j$, which is the sum of the distance of row value $i$ from the base category 1 and the distance of column value $j$ from the base category 1 for Table $1 \mathrm{~A}$, and the values of $(j-i)(i-1+j-1)$ 
Table I Data on tooth decay for women and men in Japan

\begin{tabular}{lllll}
\hline Decayed lower & \multicolumn{5}{l}{ Decayed upper teeth $(\mathrm{n})$} \\
\cline { 2 - 5 } teeth $(\mathrm{n})$ & $0-4$ & $5-8$ & $9+$ & Total \\
& $(1)$ & $(2)$ & $(3)$ & \\
\hline
\end{tabular}

(A) Women with lower and upper tooth decay

$0-4$

\begin{tabular}{|c|c|c|c|c|}
\hline (I) & $\begin{array}{l}97 \\
(97.0)^{\mathrm{a}} \\
(97.0)^{\mathrm{b}}\end{array}$ & $\begin{array}{l}62 \\
(63.4) \\
(62.7)\end{array}$ & $\begin{array}{l}15 \\
(14.8) \\
(15.8)\end{array}$ & 174 \\
\hline \multicolumn{5}{|l|}{$5-8$} \\
\hline (2) & $\begin{array}{l}20 \\
(I 8.6) \\
(19.3)\end{array}$ & $\begin{array}{l}63 \\
(63.0) \\
(63.0)\end{array}$ & $\begin{array}{l}75 \\
(73.8) \\
(73.5)\end{array}$ & 158 \\
\hline \multicolumn{5}{|l|}{$9+$} \\
\hline (3) & $\begin{array}{l}2 \\
(2.2) \\
(1.2)\end{array}$ & $\begin{array}{l}6 \\
(7.2) \\
(7.5)\end{array}$ & $\begin{array}{l}23 \\
(23.0) \\
(23.0)\end{array}$ & 31 \\
\hline Total & 119 & $13 \mid$ & 113 & 363 \\
\hline \multicolumn{5}{|c|}{ (B) Men with lower and upper tooth decay } \\
\hline \multirow[t]{2}{*}{ (I) } & $\begin{array}{l}115 \\
(115.0)^{\mathrm{a}} \\
(115.0)^{\mathrm{b}}\end{array}$ & $\begin{array}{l}55 \\
(55.7) \\
(54.8)\end{array}$ & $\begin{array}{l}25 \\
(22.9) \\
(24.2)\end{array}$ & 195 \\
\hline & & & & \\
\hline$(2)$ & $\begin{array}{l}16 \\
(15.3) \\
(16.2)\end{array}$ & $\begin{array}{l}49 \\
(49.0) \\
(49.0)\end{array}$ & $\begin{array}{l}60 \\
(61.4) \\
(61.0)\end{array}$ & 125 \\
\hline \multicolumn{5}{|l|}{$9+$} \\
\hline (3) & $\begin{array}{l}\text { I } \\
(3.1) \\
(1.8)\end{array}$ & $\begin{array}{l}7 \\
(5.6) \\
(6.0)\end{array}$ & $\begin{array}{l}21 \\
(21.0) \\
(21.0)\end{array}$ & 29 \\
\hline Total & 132 & 111 & 106 & 349 \\
\hline
\end{tabular}

Note: ${ }^{\mathrm{a}, \mathrm{b}}$ Maximum likelihood estimates of expected frequencies for the DIPS-I and DIPS-II models, respectively.

(say, $s_{i j}$ ), $i<j$, which is the product of the difference between the column value $j$ and the row value $i$ and the sum $(i-1)$ $+(j-1)$, for Table 1B, (2) the values of $\left\{\hat{p}_{i j} / \hat{p}_{j i}\right\}, i<j$, for Table $1 \mathrm{~A}$ and $\mathrm{B}$, obtained under the saturated model, and (3) the values of $\left\{\hat{p}_{i j} /\left(\hat{p}_{j i} d_{i j}\right)\right\}, i<j$, for Table $1 \mathrm{~A}$ and the values of $\left\{\hat{p}_{i j} /\left(\hat{p}_{j i} s_{i j}\right)\right\}, i<j$, for Table $1 \mathrm{~B}$, obtained under the saturated model.

For Table 1A, it is likely that the odds $\left\{p_{i j} / p_{j i}\right\}, i<j$, may be proportional to the sum of the distance, ie, $(i-1)+(j-1)$. Also for Table $1 \mathrm{~B}$, it is likely that the odds $\left\{p_{i j} / p_{j i}\right\}, i<j$, may be proportional to the product of the difference $(j-i)$ and the sum $(i-1)+(j-1)$. So we are interested in considering models which have such structures. Therefore, the present paper proposes new asymmetry models and analyzes the data in Table 1 using these new models.

\section{Materials and methods}

\section{Reviews of statistical models}

Being models which indicate the structure of asymmetry probability, the conditional symmetry model ${ }^{3}$ and the diagonals-parameter symmetry model ${ }^{4}$ are considered. The linear column-parameter symmetry model ${ }^{1}$ is considered and used for the data in Table 1.

The diagonals-parameter symmetry model is given as:

$$
\frac{p_{i j}}{p_{j i}}=\delta_{j-i}(i<j)
$$

A special case of the diagonals-parameter symmetry model is derived by making $\delta_{1}=\ldots=\delta_{r-1}(=\delta)$, ie, the conditional symmetry model, and another is derived by making $\delta_{1}=\ldots=\delta_{r-1}=1$, ie, the symmetry model. ${ }^{5,6}$

Also, the linear column-parameter symmetry model is given as:

$$
\frac{p_{i j}}{p_{j i}}=\xi^{j-1}(i<j)
$$

For the data in Table 1, the linear column-parameter symmetry model indicates that the probability that a woman's (man's) grade of lower tooth decay is $i$ and her (his) grade of upper tooth decay is $j(>i)$ is $\xi^{j-1}$ times higher than the probability that her (his) grade of upper tooth decay is $i$ and her (his) grade of lower tooth decay is $j$.

\section{New models}

We shall propose two new models. First, consider a model as follows:

$$
\frac{p_{i j}}{p_{j i}}=d_{i j} \theta(i<j),
$$

where $d_{i j}=(i-1)+(j-1)$. This indicates that the odds, $\left\{p_{i j} / p_{j i}\right\}$ for $i<j$ are proportional to the sum of the distance of row value $i$ from the base category 1 and the distance of column value $j$ from the base category 1 . Therefore, we will refer to this model as the distance-proportional symmetry I (DIPS-I) model.

For the data in Table 1, the DIPS-I model indicates that the probability that a woman's (man's) grade of lower tooth decay is $i$ and her (his) grade of upper tooth decay is $j(>i)$ is $d_{i j} \theta$ times higher than the probability that the woman's (man's) grade of upper tooth decay is $i$ and her (his) grade of lower tooth decay is $j$. If $\theta>1$, we can see that a woman's (man's) upper teeth are worse than her (his) lower teeth, and this tendency becomes stronger as the numbers of decayed teeth increase.

Secondly, consider a model as follows:

$$
\frac{p_{i j}}{p_{j i}}=s_{i j} \gamma(i<j)
$$


Table 2 Values of $(I)\left\{d_{i j}\right\}(i<j)$ for Table IA and $\left\{s_{i j}\right\}(i<j)$ for Table IB, $(2)\left\{\hat{p}_{i j} / \hat{p}_{j i}\right\}(i<j)$ for Table IA and B, and (3) $\left\{\hat{p}_{i j} /\left(\hat{p}_{j i} d_{i j}\right)\right\}(i<j)$ for Table IA and $\left\{\hat{p}_{i j} /\left(\hat{p}_{j i} s_{i j}\right)\right\}(i<j)$ for Table IB

\begin{tabular}{|c|c|c|c|c|c|}
\hline \multicolumn{6}{|c|}{ (I) $\left\{d_{i j}\right\}$ and $\left\{s_{i j}\right\}$} \\
\hline \multicolumn{3}{|c|}{$d_{i j}$} for Table IA & \multicolumn{3}{|c|}{$s_{i j}$} for Table IB \\
\hline & $j=2$ & 3 & & $j=2$ & 3 \\
\hline$i=1$ & I & 2 & $i=1$ & I & 4 \\
\hline 2 & - & 3 & 2 & - & 3 \\
\hline \multicolumn{6}{|c|}{ (2) $\left\{\hat{\boldsymbol{p}}_{i j} / \hat{\boldsymbol{p}}_{j i}\right\}$} \\
\hline \multicolumn{3}{|c|}{ For Table IA } & For $\mathrm{Ta}$ & & \\
\hline & $j=2$ & 3 & & $j=2$ & 3 \\
\hline$i=1$ & 3.1 & 7.5 & $i=1$ & 3.44 & 25 \\
\hline 2 & - & 12.5 & 2 & - & 8.57 \\
\hline \multicolumn{6}{|c|}{ (3) $\left\{\hat{p}_{i j} /\left(\hat{p}_{j i} d_{i j}\right)\right\}$ and $\left\{\hat{p}_{i j} /\left(\hat{p}_{j i} s_{i j}\right)\right\}$} \\
\hline \multicolumn{3}{|c|}{$\hat{p}_{i j} /\left(\hat{p}_{i} d_{i j}\right)$} for Table IA & \multicolumn{3}{|c|}{$\hat{p}_{i j} /\left(\hat{p}_{j i} s_{i j}\right)$} for Table IB \\
\hline & $j=2$ & 3 & & $j=2$ & 3 \\
\hline$i=1$ & 3.1 & 3.75 & $i=1$ & 3.44 & 6.25 \\
\hline 2 & - & 4.17 & 2 & - & 2.86 \\
\hline
\end{tabular}

where $s_{i j}=(j-i)\{(i-1)+(j-1)\}$. This indicates that the odds $\left\{p_{i j} / p_{j i}\right\}$ for $i<j$, are proportional to the product of the difference between the column value $j$ and the row value $i$ and the sum, $(i-1)+(j-1)$. We shall denote this model as the distance-proportional symmetry II (DIPS-II) model.

For the data in Table 1, if $\gamma>1$ under the DIPS-II model, we can see that a woman's (man's) upper teeth are worse than her (his) lower teeth, and the tendency becomes stronger as the difference between the number of decayed upper teeth and number of decayed lower teeth increases, and as the total numbers of decayed teeth increase.

\section{Statistical analysis}

Let $m_{i j}$ denote the expected frequency of $\left\{n_{i j}\right\}$. Assume that $\left\{n_{i j}\right\}$ has a multinomial distribution. The maximum likelihood estimates of expected frequencies $\left\{m_{i j}\right\}$ under each model could be obtained, for example, using the NewtonRaphson method for log-likelihood equations. Each model can be tested for goodness-of-fit by, eg, the likelihood ratio Chi-squared statistic $G^{2}$ with the corresponding degrees of freedom defined by:

$$
G^{2}=2 \sum_{i=1}^{r} \sum_{j=1}^{r} n_{i j} \log \left(\frac{n_{i j}}{\hat{m}_{i j}}\right),
$$

where $\hat{m}_{i j}$ is the maximum likelihood estimate of $m_{i j}$ under the model. ${ }^{7}$ The numbers of degrees of freedom for the DIPS-I and DIPS-II models are both $(r+1)(r-2) / 2$, which equal those for the conditional symmetry and linear columnparameter symmetry models.

\section{Results}

We analyzed the tooth decay data in Table 1 using the new models. Table 3 gives the values of the likelihood ratio test statistic $G^{2}$ for each model. From Table 3 we can see that the symmetry, conditional symmetry, and diagonals-parameter symmetry models fit these data poorly; however, the linear column-parameter symmetry, DIPS-I, and DIPS-II models fit the data very well. For the data in Table 1A (ie, for women), the DIPS-I model fits somewhat better than the DIPS-II model. For the data in Table 1B (ie, for men), the DIPS-II model fits better than the DIPS-I model.

For the DIPS-I model, the maximum likelihood estimate $\theta$ is $\hat{\theta}=3.41$ using the data in Table 1A. Therefore, the probability that a woman's grade of lower tooth decay is $i$ and her grade of upper tooth decay is $j(>i)$ is estimated to be $d_{i j} \times 3.41$ times higher than the probability that her grade of upper tooth decay is $i$ and her grade of lower tooth decay is $j$. From the data in Table $1 \mathrm{~A}$, we see from $\hat{\theta}>1$ that a woman's upper teeth are worse than her lower teeth, and the tendency becomes stronger as the total number of upper and lower teeth with decay increases.

Next, applying the DIPS-II model to the data in Table 1B, the maximum likelihood estimate of $\gamma$ is $\hat{\gamma}=3.38$. Therefore, the probability that a man's grade of lower tooth decay is $i$ and his grade of upper tooth decay is $j(>i)$ is estimated to be $s_{i j} \times$ 3.38 times higher than the probability that his grade of upper tooth decay is $i$ and his grade of lower tooth decay is $j$. From the data in Table 1B, we see from $\hat{\gamma}>1$ that a man's upper tooth decay is worse than his lower tooth decay, and that the tendency becomes stronger as the difference between the number of decayed upper teeth and that of decayed lower teeth increases, and as the total numbers of decayed teeth increase.

\section{Discussion}

Readers may be interested in guidelines for choosing between the DIPS-I and DIPS-II models. We might want to choose 
Table 3 Values of likelihood ratio statistic $G^{2}$ applied to data in Table I

\begin{tabular}{|c|c|c|c|}
\hline \multirow{2}{*}{$\begin{array}{l}\text { Models } \\
\text { used }\end{array}$} & \multirow{2}{*}{$\begin{array}{l}\text { Degrees } \\
\text { of freedom }\end{array}$} & \multicolumn{2}{|l|}{$G^{2}$} \\
\hline & & Table IA & Table IB \\
\hline$S$ & 3 & 103.33* & $98.24 *$ \\
\hline CS & 2 & $9.40 *$ & $7.44 *$ \\
\hline DPS & 1 & $9.18^{*}$ & $3.72 *$ \\
\hline LCPS & 2 & 0.39 & 1.22 \\
\hline DIPS-I & 2 & 0.39 & 2.57 \\
\hline DIPS-II & 2 & 0.87 & 0.61 \\
\hline
\end{tabular}

Note: *Significant at 0.05 level.

Abbreviations: S, symmetry; CS, conditional symmetry; DPS, diagonals-parameter symmetry; LCPS, linear column-parameter symmetry; DIPS-I, distance-proportional symmetry I; DIPS-II, distance-proportional symmetry II.

the DIPS-I model if we can assume that the odds $\left\{p_{i j} / p_{j i}\right\}$, $i<j$, are proportional to the sum of the distance of a row value from the base category 1 and the distance of a column value from the base category 1 . On the other hand, we might want to choose the DIPS-II model if we can assume that the odds $\left\{p_{i j} / p_{j i}\right\}, i<j$, are proportional to the product of the difference between a column value and a row value, and the sum.

Some readers may also be interested in knowing the age distribution and other clinical characteristics of patients in Table 1 in addition to data on tooth decay. However, we took the data in Table 1 directly from another paper, ${ }^{1}$ so cannot investigate those items in detail. Therefore, it is important to perform clinical research to collect the data on decayed teeth and related characteristics in the future and to analyze and compare them with the data presented in this paper in more detail.

\section{Conclusion}

We have proposed two kinds of asymmetry models, namely, the DIPS-I and DIPS-II. These models are useful for seeing the structure of asymmetry of cell probabilities $\left\{p_{i j}\right\}$, especially for the data on tooth decay as shown in Table 1. Upper tooth decay appears worse than lower tooth decay in both men and women, and the tendency becomes stronger as the sum of numbers of upper and lower decayed teeth increases.

\section{Disclosure}

The authors report no conflicts of interest in this work.

\section{References}

1. Tomizawa S, Miyamoto N, Iwamoto M. Linear column-parameter symmetry model for square contingency tables: application to decayed teeth data. Biometrical Letters. 2006;43:91-98. Available at: http://www. up.poznan.pl/biometrical.letters/index.php? $\mathrm{p}=\mathrm{abstract} \& \mathrm{a}=2006.43 .2 .3$.

2. Kurakami H, Yamamoto K, Tomizawa S. Generalized exponential symmetry model and orthogonal decomposition of symmetry for square tables. The Open Statistics and Probability Journal. 2011;3:1-6. Available at: http://www.benthamscience.com/open/tospj/articles/V003/1TOSPJ. pdf.

3. McCullagh P. A class of parametric models for the analysis of square contingency tables with ordered categories. Biometrika. 1978;65:413-418. Available at: http://www.stat.uchicago.edu/ pmcc/pubs/paper3.pdf.

4. Goodman LA. Multiplicative models for square contingency tables with ordered categories. Biometrika. 1979;66:413-418. Available at: http:// biomet.oxfordjournals.org/content/66/3/413.short.

5. Bowker AH. A test for symmetry in contingency tables. JAm Stat Assoc. 1948;43:572-574.

6. Bishop YMM, Fienberg SE, Holland PW. Discrete Multivariate Analysis: Theory and Practice. Cambridge, MA: MIT Press; 1975.

7. Wilks SS. The large-sample distribution of the likelihood ratio for testing composite hypotheses. Annals of Mathematical Statistics. 1938;9: 60-62. Available at: http://www.jstor.org/stable/2957648?seq=1.
Open Access Medical Statistics

\section{Publish your work in this journal}

Open Access Medical Statistics is an international, peer- reviewed, open access journal publishing original research, reports, reviews and commentaries on all areas of medical statistics. The manuscript management system is completely online and includes a very quick and fair

\section{Dovepress}

peer-review system. Visit http://www.dovepress.com/testimonials.php to read real quotes from published authors. 